\title{
Impact of tritium discharged from a research reactor on concentrations in environmental water samples
}

\author{
M. Fukui, S. Kimura ${ }^{1}$ and S. Saito \\ Research Reactor Institute, Kyoto University, Kumatori-cho, \\ Sennan-gun, Osaka 590-0494, Japan \\ ${ }^{1}$ Osaka University of Pharmaceutical Sciences, Nasahara, \\ Takatsuki-city, Osaka 569-1094, Japan
}

\begin{abstract}
The distribution of environmental tritium concentrations in several samples taken near the Kyoto University Research Reactor (KURR) was studied. The KURR Institute (KURRI) supports three major sources of tritium: a $\mathrm{D}_{2} \mathrm{O}$ (heavy water) facility and a Cold Neutron Source (CNS) facility in the KURR containment, and a tritium target fabricated in an accelerator in the critical assembly building. This report focuses on estimating the rate of release of tritium from these sources into the environment, and grasping the relation between the rate and the concentrations in samples of water such as precipitation, air moisture and surface water taken near the release point. The concentrations of tritiated water (HTO) in the stack exhaust condensate were in the range $0.8-3 \mathrm{kBq} \mathrm{dm}$ though those in air in the buildings that support the HTO sources ranged from $5 \mathrm{~Bq} \mathrm{dm}^{-3}$ to $2 \mathrm{kBq} \mathrm{dm}^{-3}$. The $\mathrm{HTO}$ concentrations in the air decreased by ca. 1/500 within $300 \mathrm{~m}$ of the KURR stack, which is five times the current global level about $5 \mathrm{~km}$ off-site. Assessing the degree of attenuation of HTO concentrations in the field is informative for estimating the chronic impact of contaminants in the environment.
\end{abstract}

\section{INTRODUCTION}

At present, atmospheric releases of tritium from nuclear facilities are not a significant health hazard, and the tritium concentration in exhaust air is low [1] except for unplanned releases [2]. There is however, a continuing interest in the biological effects of tritium and its behavior in the environment due to the possibility of an increase in releases from proposed/planned fusion reactors in Japan.

KURR is reactor with a light water moderator located inland at Osaka, Japan. It was initially operated at $1 \mathrm{MW}$ in 1964 , but this was raised to $5 \mathrm{MW}$ in 1968 . The reactor is usually operated for $70-75$ hours weekly from Tuesday through Friday and about 2000 hrs yearly with a ventilation system of $7.8 \times 10^{4} \mathrm{~m}^{3} \mathrm{~h}^{-1}$. The discharge rate of radioactivity from KURR during operation at $5 \mathrm{MW}$ is $0.2-0.3 \mathrm{GBq}(\mathrm{MWh})^{-1}$ of ${ }^{41} \mathrm{Ar}$ with a concentration of ca. $(2-3) \times 10^{1} \mathrm{~Bq} \mathrm{dm}^{-3}$ in the stack exhaust. Because of the high concentration of ${ }^{41} \mathrm{Ar}$, as measured by a $22-\mathrm{dm}^{-3}$ ionization chamber, the presence of other radionuclides is usually masked by the minor releases during normal operation of the reactor; this is especially true for HTO. For this reason, routine monitoring of HTO in the exhaust has been carried out quarterly using a liquid scintillation counter (LSC) for water samples collected by a condenser during the operation of KURR.

Despite more than 30 years of operation, no field data on HTO concentrations to estimate the environmental impact of KURR has been accumulated. Assessing the degree of attenuation of HTO concentrations in the field is important for reasons of public health. Therefore, HTO concentrations in water samples such as air moisture taken around the KURR site were measured to elucidate the level of chronic contamination in the environment. The information may facilitate estimating radiological impact in cases of unexpected release of radionuclides. 


\section{SAMPLING AND METHODS}

The specific activity in the air/exhaust condensate collected for a few hours with a condenser and/or dehumidifier was measured for an aliquot of $1 \mathrm{~cm}^{3}$ which was mixed with $10 \mathrm{~cm}^{3}$ of scintillation cocktail (ACSII). Samples were allowed for radiometric assay for 60 minutes with detection limit, $6.8 \times 10^{1} \mathrm{~Bq} \mathrm{dm}^{-3}$. For samples with concentrations below the detection limit, a low background counting technique was adopted, where purified water $(8$ $\mathrm{cm}^{3}$ ) condensed by electrolysis was mixed with $8 \mathrm{~cm}^{3}$ of liquid scintillation cocktail (UltimaGold LLT, Packard Co.) in a $20 \mathrm{ml}$ vial. This sample was stored in a dark place for $24 \mathrm{hrs}$, and subjected to radiometric assay for $\mathbf{5 0 0}$ minutes.

The locations of water samples taken in the field (Nos.127) are shown in Fig. 1. Surface/tap water samples (Nos.28-33) taken off-site more than a few $\mathrm{km}$ apart were not shown in the figure for the sake of brevity.

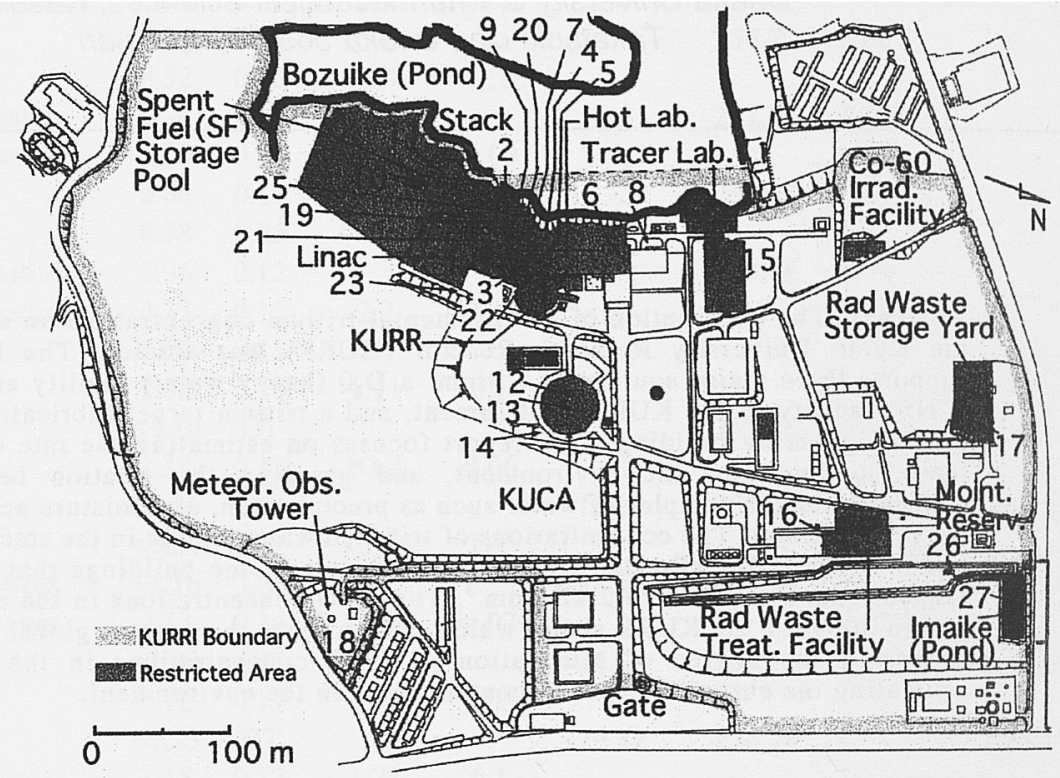

Fig.1: KURRI area and sampling locations (Nos.1-27). Water samples (Nos.1-18) were taken as exhaust/air moisture. Samples (Nos.19-25) were of precipitation. Locations, Nos.26-27 are the lower reaches of effluent, where runoff joins.

\section{RESULTS AND DISCUSSION}

\subsection{HTO concentrations in air moisture near the sources and the emission rate}

Figure 2 shows HTO concentrations in condensate in the KURR stack exhaust (No.2) monitored quarterly for twenty years. It indicates that the concentration has not increased much except for a term of unexpected release of heavy water. During one and half years from May 1987 to November 1988, a small amount of heavy water (ca.30 $\mathrm{dm}^{3}$ ) leaked from the $2 \mathrm{~m}^{3} \mathrm{D}_{2} \mathrm{O}$ facility, resulting in leakage of about $0.34 \mathrm{TBq}$ of tritium into the KURR containment building [3].

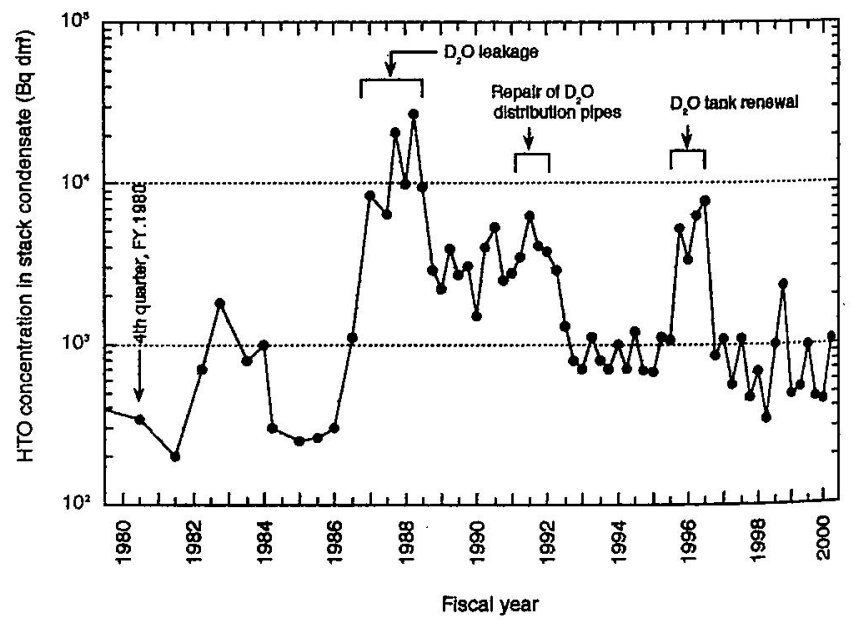

Fig.2: HTO concentrations in stack condensate collected twice a year (1980-1987) or quarterly (1988-). 
As shown in Fig.2, a peak concentration, $27 \mathrm{kBq} \mathrm{dm}^{-3}$, in the stack condensate, was observed on the routine monitoring in the third quarter of 1988 .

After the leak, low peaks of concentration, ranging from 5 to $10 \mathrm{kBq} \mathrm{dm}^{-3}$, were recorded due to a small leak of heavy water during a period of renewal of distribution pipes of the $\mathrm{D}_{2} \mathrm{O}$ facility (1990 to 1992) and the $\mathrm{D}_{2} \mathrm{O}$ tank in 1996. The monitoring as carried out on a batch basis for the water samples collected as condensate may have overlooked higher concentrations in the exhaust. This was confirmed by monitoring that showed a peak concentration of $18 \mathrm{kBq} \mathrm{dm}^{-3}$ on a monthly basis during $1990-1992$ and $80 \mathrm{kBq} \mathrm{dm}^{-3}$ on a daily basis during December 1991 .

Figure 3 shows recent data for various water samples from the environment including air condensate in facilities together with location numbers as shown in Fig.1. The HTO concentrations in air condensate both in the KURR containment building during venting cessation (sampling location: No.1, the volume of reactor containment: ca.1.7 $\times 10^{4} \mathrm{~m}^{3}$ ) and in stack exhaust (No.2) were a few $\mathrm{kBq} \mathrm{dm}^{-3}$. This resuled in an annual HTO emission from the KURR stack of about $2 \mathrm{GBq}^{-1}$, as estimated based on venting conditions.

Specific activities in air condensate in the CA building which supports another source of tritium emission, were lower than those in the KURR exhaust, ranging from $3 \times 10^{-2}$ to $4 \times$ $10^{-1} \mathrm{kBq} \mathrm{dm}^{-3}$ (No.12) during continuous ventilation working. During daily operation of venting for $8 \mathrm{hrs}$, the concentrations in the building increased to $1 \mathrm{kBq} \mathrm{dm}^{-3}$ in the morning just before the venting commenced and decreased in the afternoon (No.13). This pattern of emission continued every day but to a lesser extent due to daily venting from June 29 to July $2^{\text {nd }}, 1998$. Because the venting rate and concentrations were lower than in KURR, the rate of emission from the CA building is estimated at below $1 / 10$ that for KURR.

\subsection{Environmental monitoring of air condensate}

The HTO concentrations in the filter chamber room (No.3 in Fig.3) where exhaust air from the KURR containment building and Hot laboratory has been treated with both glass wool and HEPA filters, were (1-4) $\times 10^{2} \mathrm{~Bq} \mathrm{dm}^{-3}$. This level is about $1 / 10$ of that in the stack exhaust, indicating a small leak of exhaust air from the exhaust chamber system into the room. In the fuel pool room (No.4) adjacent to the filter chamber room, but isolated by the wall, the same level of HTO, $4 \times 10^{2} \mathrm{~Bq} \mathrm{dm}^{-3}$, as in the chamber room was recorded. This stems from the air moisture of water in the fuel pool that is connected to the primary coolant via a canal, which contains a few $\mathrm{kBq} \mathrm{dm}^{-3}$ of HTO. Further from the chamber room (No.5 and No.6), the HTO concentrations decreased to (1-2) $\times 10^{1} \mathrm{~Bq} \mathrm{dm}^{-3}$, due to air diffusion in the Hot laboratory.

In the spent fuel pool building (SF: No.10), the HTO concentrations in the air condensate were (0.7-1.0) $\times 10^{3} \mathrm{~Bq} \mathrm{dm}^{-3}$ which is $1 / 3-1 / 2$ of that in the pool water itself. The origin of the HTO in this building may be the $2 \mathrm{~m}^{3}-\mathrm{D}_{2} \mathrm{O}$ tank replaced in the KURR containment building in 1996 and stored in the SF building. In the tracer laboratory (TL: No.15), the HTO concentration was $6 \mathrm{~Bq} \mathrm{dm}^{-3}$ in air moisture collected on the roof.

The HTO concentration in a laboratory (WD: No.16) in which uses an unsealed tritium source was $1.5 \times 10^{2} \mathrm{~Bq} \mathrm{dm}^{-3}$. That in the passage adjacent to the laboratory was $1 \times 10^{1} \mathrm{~Bq}$ $\mathrm{dm}^{-3}$, that is, $1 / 15$ of the value inside the room, indicating a small leak of HTO from the laboratory to the passage.

As shown in Fig.3, HTO concentrations in atmospheric moisture observed outside the buildings (Nos.7, $8,9,11,14,15$ ) which support HTO sources ranged from 2 to $10 \mathrm{~Bq} \mathrm{dm}^{-3}$. Whereas the HTO concentrations in the atmospheric moisture collected at the meteorological tower (No.18) which is about $300 \mathrm{~m}$ from the KURR stack, was $4 \mathrm{~Bq} \mathrm{dm}^{-3}$, not so different from those observed just outside the buildings. More data should be collected to elucidate whether the level of HTO in atmospheric moisture outside the facilities with small emissions is chronically contaminated or not. 

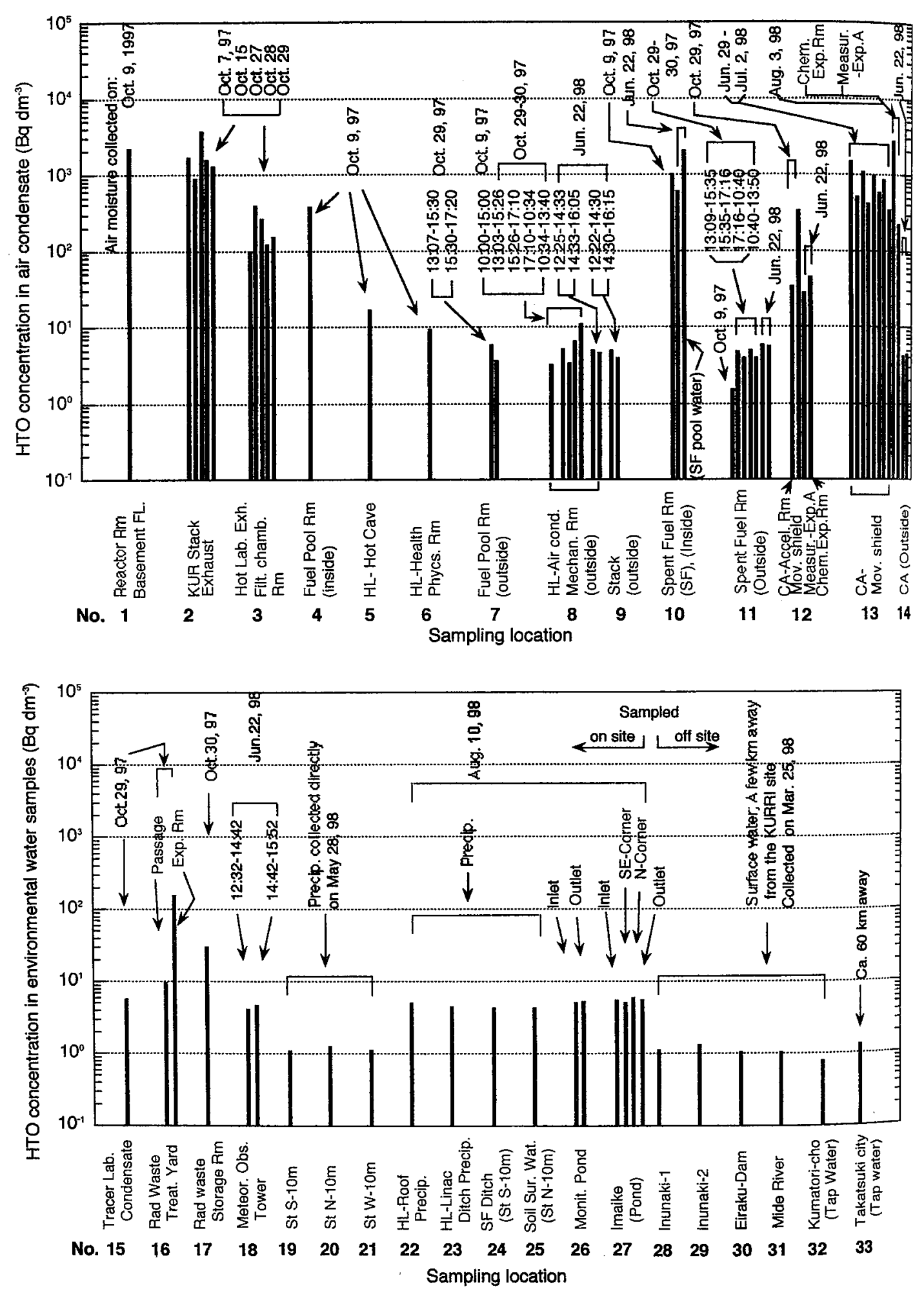

Fig.3: HTO concentrations in air moisture (Nos.1-18), precipitation (Nos.19-25), surface water in an effluent stream (Nos.26-27) and surface/tap water sampled offsite (Nos.28-33). 


\subsection{HTO emissions in the aquatic system and monitoring of water samples in the field}

\subsubsection{Amount of HTO discharged as effluent after radioactive liquid waste treatment}

Tritium, at a low concentration, is the radionuclide usually detected in wastewater derived from both the KURR primary cooling system and laboratories. The tritium produced in light water reactors (LWRs) originates from ternary fission of the nuclear fuel, the activation of lithium/boron isotopes, and $(n, \gamma)$ reactions with deuterium dissolved in the primary coolant. The low level radioactive liquid waste is stored in a $30 \mathrm{~m}^{3}$ tank before treatment by flocculation and/or an ion exchange resin method. The HTO concentration in the KURR light water moderator had a constant value of about $2 \times 10^{1} \mathrm{kBq} \mathrm{dm}^{-3}$ before May 1987 . The small amount of heavy water that leaked from a $2 \mathrm{~m}^{3}$ tank installed adjacent to the reactor core gradually increased the HTO concentration in the $30 \mathrm{~m}^{3}$ primary coolant water fivefold within ten months of the supposed date of leakage. Recovery processes and surveys of the leakage point were carried out from September 1988 to March 1990 together with longterm monitoring of air [3]. This incident and the remediation associated with it led to an increase in the amount of HTO released into the KURR aquatic system as shown in Fig.4. Figure 4 shows the average concentrations per year derived from the gross tritium activity and the wastewater volume discharged since April 1987 and the annual amount of HTO discharged. The smallest discharge, $6.7 \times 10^{1} \mathrm{MBq}$, was recorded during the period from April 1987 to March 1988 (Fiscal Year (FY), 1987) before the HTO leak had been discovered. Whereas, amounts one to two orders of magnitude larger have been discharged for several years since FY 1988 due to the remediation process. At present, the annual amount of HTO discharge falls at around $0.5 \mathrm{GBq}^{-1}$ since 1992 , almost $1 / 4$ of that from atmospheric release. The total (atmospheric and aqueous) rate of emission of HTO into the environment from the facilities in the KURRI is estimated to be $2.5 \mathrm{GBq}^{-1}$ at most.

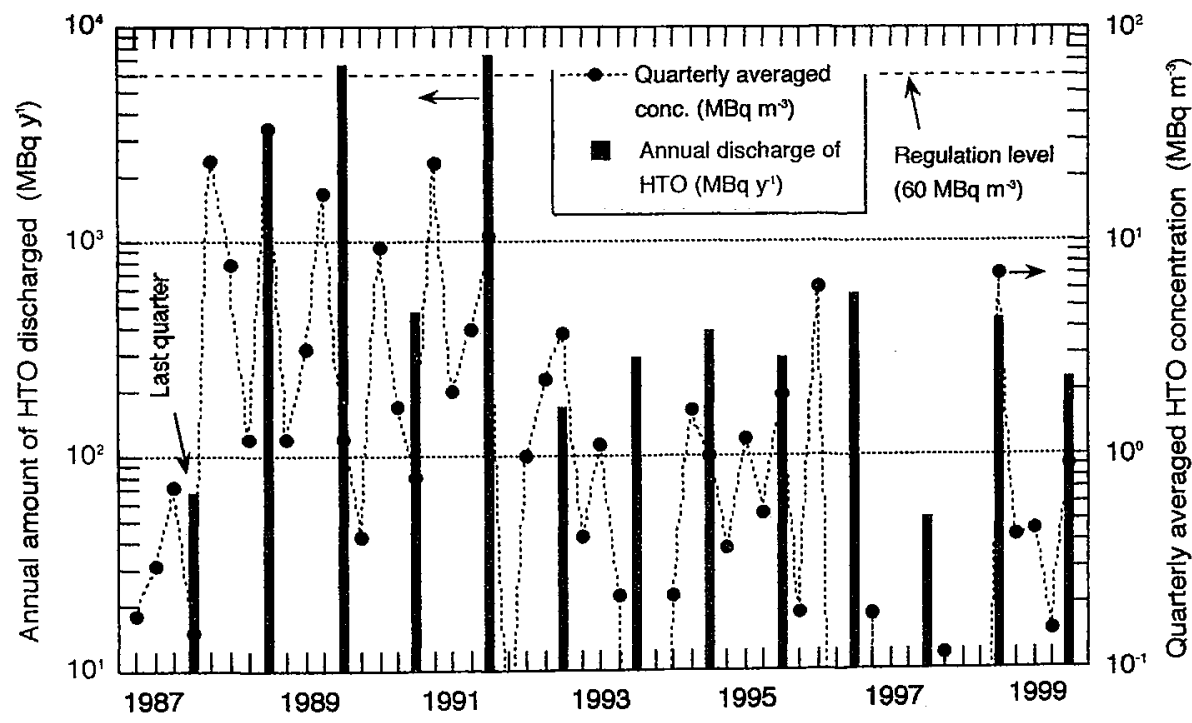

Fiscal year

Fig. 4: HTO concentrations in effluent averaged quarterly $\left(\mathrm{MBq} \mathrm{m}^{-3}\right)$ and annual amount of HTO discharged as liquid waste $\left(\mathrm{MBq} \mathrm{\textrm {y } ^ { - 1 }}\right)$. 


\subsubsection{HTO concentrations in water samples taken in the field}

After treatment of rad waste with flocculation-coagulation, ion exchange and/or evaporation, effluent has been discharged intermittently into a retention pond (named Imaike: No.27) via a monitoring pond $\left(10 \times 7 \mathrm{~m}^{2}\right.$ and $1 \mathrm{~m}$ deep: No.26 in Fig.1). The impoundment and water volume of Imaike were estimated as $0.11 \mathrm{ha}$ and $1.7 \times 10^{3} \mathrm{~m}^{3}$, respectively. At the KURRI site, the level for the HTO concentration in effluent per batch of treated wastewater has been set at $6 \times 10^{1} \mathrm{kBq} \mathrm{dm}$; equivalent to the average HTO concentration for quarterly release, as determined by the law for the nuclear power regulation in Japan.

The surface water samples were taken at sites No.26 and No.27 (4 points: Southwest (inlet), Southeast, North center, Northeast (outlet)) in the effluent stream. As shown in Fig. 3 these surface water samples showed the same levels of HTO concentrations, 5-7 Bq $\mathrm{dm}^{-3}$ (Nos.26 -27). The levels in the aquatic environment depend on the discharge scenarios, i.e., the concentration in effluent and the time elapsed after the last emission. During the dry season, the water in Imaike was replaced within a week [4]. The concentrations were low and rather uniform, indicating no influence of effluent in the aquatic system, because the sampling was done on August, 1998, two weeks after the last discharge.

HTO concentrations in precipitation directly collected in a vessel $10 \mathrm{~m}$ from the KURR stack in three directions (South: No.19, North: No.20, West: No.21) were about $1 \mathrm{~Bq} \mathrm{dm}$. Nevertheless, those in standing rainwater on the roof of the Hot laboratory (No.22), in ditches (No.23 and No.24), and collected on the ground near the stack (No.25) were 4-5 Bq $\mathrm{dm}^{-3}$. This suggests that moisture with a low level of HTO may attach on the building, soil and environmental flora.

HTO concentrations in river water more than a few $\mathrm{km}$ from the site (Nos.28-31) and tap water (Nos. 32-33) were the same, $1.0 \pm 0.2 \mathrm{~Bq} \mathrm{dm}^{-3}$, as those in precipitation collected directly in a vessel (Nos.19-21), which shows the current global level of HTO in the environment.

\section{CONCLUSIONS}

HTO concentrations in the atmospheric moisture samples collected inside the facilities with HTO sources ranged from $5 \mathrm{~Bq} \mathrm{dm}{ }^{-3}$ to $4 \mathrm{kBq} \mathrm{dm}^{-3}$, though they decreased with the distance from the source. On the other hand, HTO concentrations in all the atmospheric moisture samples collected in the field outside of the facilities with HTO sources did not differ from those in samples of water as precipitation on soil, drainage via the roof and effluent in the aquatic drainage system. They ranged from 2 to $10 \mathrm{~Bq} \mathrm{dm}^{-3}$ in the areas covered by this study within a few hundred meters of the sources where about $2.5 \mathrm{GBq}$ of HTO has been released yearly. That is, the emission elevated the HTO concentration in the terrestrial environment of the study area by $2-10$ fold of the current global level.

The next step is to determine the changes in HTO concentrations in air moisture with time and in environmental vegetation.

\section{References}

[1] Langhorst, S. M., Morris, J.S. and Bull, S.R., Health Phys. 40 (1981) 823-827.

[2] Kurzeja, R.J., Murphy Jr, C.E. and Taylor, R.W., Fusion Technol. Part B, 14 (1988) 1111-1114.

[3] Fukui, M., Health Phys. 62 (1992) 144-154.

[4] Fukui, M., Migration and Modelling of tritium in waste water reservoirs and a retention pond, Freshwater and estuarine radioecology, Lisbon, Portgal, 21-25 March 1994, G. Desmet et al. Eds. (Elsevier, Amsterdam, 1997) pp.151-164. 